\title{
Artikel
}

\section{Strategisch procederen in het milieurecht: bestuursrechter en civiele rechter}

Prof. mr. G.A. (Gerrit) van der Veen*

\section{Inleiding}

Het strategisch procederen in het milieurecht staat in de belangstelling. Strategisch procederen kan worden omschreven als het inzetten van het recht ter behartiging van maatschappelijke belangen. Meer in het bijzonder kan daaronder worden verstaan het aan de rechter voorleggen van een groot maatschappelijk vraagstuk dat één of meer concrete casus overstijgt. Partijen die dat als hun taak zien, hebben het tij mee en hebben opvallende successen geboekt.

Zo hebben tot de verbeelding sprekende zaken over klimaatverandering (Urgenda tegen de Staat) en luchtkwaliteit (Milieudefensie tegen de Staat) interessante vonnissen opgeleverd. ${ }^{1}$ In beide zaken werd een groot maatschappelijk vraagstuk aan de rechter voorgelegd. Deze bleek daar gevoelig voor. In beide zaken werd de Staat veroordeeld om meer en/of sneller te reageren op dat vraagstuk en voortvarender maatregelen te treffen dan de Staat zelf van plan was. Niet alle ontwikkelingen hoeven echter te beklijven. Enerzijds staat nog niet vast dat grote maatschappelijke vraagstukken duurzaam aan de rechter voorgelegd kunnen worden. ${ }^{2}$ Anderzijds blijken verschillende leerstukken inzetbaar te zijn om de

* Prof. mr. G.A. van der Veen is advocaat bij AKD te Rotterdam, bijzonder hoogleraar milieurecht aan de Rijksuniversiteit Groningen en lid van de redactie van TO.

1. Rb. Den Haag 24 juni 2015, ECLI:NL:RBDHA:2015:7145 (Urgenda) en Rb. Den Haag (vz.) 7 september 2017, ECLI:NL:RBDHA:2017:10171 (Luchtkwaliteit)

2. Hof Den Haag 22 mei 2018, ECLI:NL:GHDHA:2018:1128 (Luchtkwaliteit). rechter ook in appel tot een harde veroordeling van de Staat te brengen. ${ }^{3}$

Dit artikel gaat nader in op het strategisch procederen in het milieurecht en begint met een korte terreinverkenning. Aan de orde komt welke mogelijkheden al bestonden om vraagstukken aan de rechter voor te leggen, en wat nu daadwerkelijk nieuw is. Vervolgens wordt bezien welke beperkte mogelijkheden de bestuursrechter heeft om zich over grote maatschappelijke vragen te uiten, en hoe de burgerlijke rechter met grote maatschappelijke vragen recent is omgegaan. Daarbij komen twee aandachtspunten van civiele procedures aan de orde. Deze leiden tot de conclusie dat het nog maar de vraag is of bereikte successen beklijven.

\section{Terreinverkenning}

Strategisch procederen gaat over de manier waarop het recht wordt ingezet ter behartiging van matschappelijke belangen. Met procedures over maatschappelijke belangen als luchtkwaliteit en het bereiken van klimaatdoelstellingen wordt niet alleen een maatschappelijk debat bevorderd, maar komen ook vragen op over de rol van het recht en de rechter. ${ }^{4}$

Het behartigen van maatschappelijke belangen via de inzet van het recht en de rechter is geenszins nieuw. Expliciete procesrechtelijke bepalingen in het bestuursrecht en het burgerlijk recht bevestigen de mogelijkheid

3. Hof Den Haag 9 oktober 2018, ECLI:NL:GHDHA:2018:2591, AB 2018/417 m.nt. Ch.W. Backes en G.A. van der Veen (Urgenda).

4. Vgl. N. van den Biggelaar, voorwoord bij R. Stolk e.a., Strategisch procederen in het milieurecht (preadviezen Jonge VAR, nr. 17), Den Haag: Boom juridisch 2017. 
voor belangenbehartigers om in rechte op te treden ter verdediging van het door hen behartigde belang.

Volgens art. 1:2 lid 1 en 3 van de Algemene wet bestuursrecht (Awb) wordt onder belanghebbende verstaan degene wiens belang rechtstreeks bij een besluit is betrokken, en gelden bij rechtspersonen als hun belangen mede de algemene en collectieve belangen die zij krachtens hun doelstellingen en blijkens hun feitelijke werkzaamheden in het bijzonder behartigen. Indien kortom een algemeen of collectief belang rechtstreeks bij een (appellabel) besluit is betrokken, hebben behartigers van dat algemene of collectieve belang toegang tot de bestuursrechtelijke rechtsbescherming en dus tot de bestuursrechter. ${ }^{5}$ Dat wil vervolgens overigens niet zeggen dat al hun beroepsgronden tot vernietiging kunnen leiden, omdat het relativiteitsvereiste van art. 8:69a Awb aan gegrondverklaring in de weg kan staan. ${ }^{6}$

Art. 3:305a lid 1 van het Burgerlijk Wetboek (BW) leert dat een stichting of vereniging met volledige rechtsbevoegdheid een rechtsvordering kan instellen die strekt tot bescherming van gelijksoortige belangen van andere personen, voor zover zij deze belangen ingevolge haar statuten behartigt. Het artikel bevestigt de regel uit het arrest Nieuwe Meer, waarin de Hoge Raad onder meer overwoog dat de enkele doelomschrijving van een rechtspersoon deze nog niet bevoegd maakt om ter zake van aantasting van de belangen waarvan zij blijkens die omschrijving de behartiging op zich heeft genomen, bij de burgerlijke rechter een vordering in te stellen, maar dat daarop uitzonderingen denkbaar zijn, onder meer omdat de belangen die bij een vordering als de onderhavige - in wezen strekkende tot het verkrijgen van een verbod tot verdere aantasting van het milieu - betrokken zijn, zich lenen tot een 'bundeling' als door het optreden in rechte van de milieuverenigingen tot stand is gebracht. Bij gebreke van de mogelijkheid van een zodanige bundeling zou een efficiënte rechtsbescherming tegen een dreigende aantasting van deze belangen niet onaanzienlijk kunnen worden bemoeilijkt. ${ }^{7}$

De via art. 3:305a BW gevestigde toegang tot de civiele rechter brengt vervolgens met zich dat belangenbehartigers zich aldaar ook op rechtstreeks werkende verdragsbepalingen kunnen beroepen, ongeacht of in het betreffende verdrag zelf ook of juist niet een rechtsbeschermingsmogelijkheid voor hen is voorzien. ${ }^{8}$

\section{What's old?}

Strategisch procederen is niet nieuw, waar het gaat om procedures tegen afzonderlijke bedrijven en/of afzonderlijke bestuursrechtelijke besluiten over vergunningverlening of handhaving.
Uit de civiele hoek zijn de procedures bekend van organisaties tegen Kuunders en tegen de Covra. Uit het arrest Kuunders volgde dat milieuorganisaties in een civiele procedure tegen een veehouderij kunnen ageren in verband met haar handelen zonder toereikende vergunning, ook ingeval zij in een met voldoende waarborgen omklede bestuursrechtelijke rechtsgang hebben kunnen procederen tegen een weigering om bestuursdwang toe te passen. De burgerlijke rechter, die een vordering tot verbod ontvankelijk acht, nadat de bestuursrechter de overheid niet tot bestuursdwang gehouden heeft geoordeeld, beslist niet hetzelfde punt. ${ }^{9}$ Ook in Covra stond de civielrechtelijke weg tegen het betrokken bedrijf in principe open, al leende de civiele rechter zich niet voor een hertoetsing van (belangen)afwegingen die vrij kort daarvoor al uitgebreid in bestuursrechtelijke procedures aan de orde waren gekomen. ${ }^{10}$

In het bestuursrecht zijn procedures tegen vergunningverlenende of (gesteld) onvoldoende handhavende overheden geregeld aan de orde. Ook in kleine oorden als Vlagtwedde is nog wel een procedure te vinden over intrekkingen van vergunningen op verzoek van belangengroepen. ${ }^{11}$ Beroepen tegen verleende vergunningen komen geregeld voor. ${ }^{12}$ In 2008 heeft de bestuursrechter de ontvankelijkheid voor belangengroeperingen wat beperkt. Tot grote belemmeringen lijkt deze jurisprudentie echter niet te hebben geleid. ${ }^{13}$ Ook overigens hebben belangengroeperingen ruim baan, mede door de lage griffierechten en de nagenoeg niet toegepaste mogelijkheid tot veroordeling tot betaling van de (ook al beperkte) proceskosten van andere partijen.

\section{What's new?}

Nieuw lijkt de 'bovenindividuele insteek', zijnde het aan de rechter voorleggen van een kwestie die een concrete casus ontstijgt. Het gaat dan niet meer om het behartigen van algemene belangen over de band van concrete gevallen, maar om het aan de orde stellen van een maatschappelijk vraagstuk dat nu juist niet is opgehangen aan één concrete vergunningverlening, handhavingsactie of andere bestuursrechtelijke beschikking. Het gaat veeleer om het voorleggen van een vraagstuk dat vertaald is (of zelfs nog geheel of gedeeltelijk moet worden) in algemeen verbindende voorschriften en/of in ander gedrag van (vooral) de overheid. Het lijkt erop dat aldus aan de rechter niet zozeer wordt voorgelegd of een concreet geval wel voldoet aan de geldende regels, maar meer of de geldende regels en/of het handelen van de overheid in het algemeen wel voldoen aan de standaarden die belangengroeperingen graag zien. Illustratief is 
een van de vorderingen in de (bodem)procedure inzake luchtkwaliteit. Milieudefensie vorderde onder meer dat de Staat zich zou gaan houden aan WHO-guidelines voor luchtkwaliteit, die strenger zijn dan de verplichtingen die voor de Staat voortvloeien uit Richtlijn 2008/50/EG en de Wet milieubeheer (Wm). ${ }^{14}$

\section{What's new en de bestuursrechter?}

Het lijkt erop dat de bestuursrechter vrij weinig mogelijkheden heeft om zich te buigen over bovenindividuele casus. Dat heeft een formele en een materiële oorzaak. De bestuursrechter is bekneld door het besluitbegrip van art. 1:3 Awb en de uitsluiting van beroep tegen algemeen verbindende voorschriften. Het bestuursprocesrecht is en blijft beschikkingenprocesrecht. De bovenindividuele insteek verdraagt zich niet met dat beschikkingenprocesrecht. De herhaalde pleidooien voor directe toetsing van algemeen verbindende voorschriften door de bestuursrechter hebben nog niet tot verbreding van de rechtsmacht van de bestuursrechter geleid. ${ }^{15}$ Wanneer de bestuursrechter zich dan toch over algemeen verbindende voorschriften buigt, doet hij dat bij wijze van exceptieve toetsing. Over de band van de beoordeling van een beschikking kan aldus ook een oordeel worden gegeven over een betrokken algemeen verbindend voorschrift. Die exceptieve toetsing is vooralsnog echter tamelijk terughoudend. De bestuursrechter stelt vrij weinig inhoudelijke eisen aan algemeen verbindende voorschriften. ${ }^{16}$

Dat wil niet zeggen dat de bestuursrechter nimmer ingrijpt. De bestuursrechter is wel kritisch gebleken bij de toetsing van besluiten die gebaseerd zijn op een 'programmatische aanpak', zijnde de programmatische aanpak stikstof (PAS). De bestuursrechter was niet overtuigd van de rechtmatigheid van de PAS in het licht van de Habitatrichtlijn en heeft daarom prejudiciële vragen aan het Hof van Justitie van de EU gesteld. ${ }^{17}$ Omdat vele beschikkingen ten dele op de PAS zijn gegrond, is een veelheid van beroepsprocedures stil komen te liggen, met onzekerheid over de rechtmatigheid van vele beschikkingen tot gevolg. ${ }^{18}$ In dit geval is dus wel sprake van een bovenindividuele vraagstelling die vele beschikkingen raakt.

In het algemeen is de bestuursrechter echter niet de beslechter van maatschappelijke vraagstukken die een

14. Rb. Den Haag 27 december 2017, ECLI:NL:RBDHA:2017:15380.

15. Zie o.m. Y.E. Schuurmans, Van bestuursrechtelijke detailhandel naar maakindustrie (oratie Leiden), 2015 en R.J.B. Schutgens, Rechtsbescherming tegen algemene regels: tijd om de Awb te voltooien, in: W.J.M. Voermans e.a., Algemene regels in het bestuursrecht (preadviezen VAR, nr. 158), Den Haag: Boom juridisch 2017.

16. Zie nader conclusie van staatsraad A-G Widdershoven bij ABRvS 22 december 2017, ECLI:NL:RVS:2017:3557.

17. ABRvS 17 mei 2017, ECLI:NL:RVS:2017:1260 en ABRvS 17 mei 2017, ECLI:NL:RVS:2017:1259.

18. Zie nader R.H.W. Frins, PAS op de plaats... en nu?, TBR 2017/93 en TBR 2017/112. concrete vergunningverlening, handhavingsactie of andere bestuursrechtelijke beschikking overstijgen.

Waar het mogelijkerwijs wél zou kunnen gaan om vertalingen van maatschappelijke vraagstukken in één of meer concrete besluiten, verlangt de bestuursrechter van procederende partijen dat zij duidelijk maken in hoeverre het aangesproken bestuursorgaan daadwerkelijk zelf concrete bevoegdheden heeft om besluiten te nemen. Daarop strandde een procedure tegen de staatssecretaris. Volgens appellanten diende hij maatregelen te treffen ter bevordering van de luchtkwaliteit. De bestuursrechter constateerde dat besluitvorming over specifieke maatregelen vaak door gemeentelijke bestuursorganen diende te geschieden. Bij de staatssecretaris waren appellanten dan ook aan het verkeerde adres. ${ }^{19}$

\section{What's new en de civiele rechter?}

Hoewel civiele rechtspraak inzake Urgenda en Luchtkwaliteit de indruk kan wekken dat de civiele rechter de deur voor strategisch procederen in zaken met een bovenindividuele insteek wijd opengezet heeft, zijn in ieder geval twee duidelijke beperkingen te noteren. Deze hangen samen met de rechtsmachtverdeling tussen de civiele rechter en de bestuursrechter.

Ten eerste zal de civiele rechter zich niet inhoudelijk over vraagstukken buigen wanneer deze via bestuursrechtelijke procedures tegen besluiten aan de bestuursrechter voorgelegd hadden kunnen worden. De leer van de formele rechtskracht brengt met zich dat onherroepelijk geworden beschikkingen niet alsnog aantastbaar worden, wanneer nadien in een andere bestuursrechtelijke procedure het onderliggende algemeen verbindende voorschrift sneuvelt. De formele rechtskracht van de beschikking prevaleert dan. ${ }^{20}$ Dat is echter bekende jurisprudentie. ${ }^{21}$ Deze heeft in ieder geval het voordeel van de eenvoud, in die zin dat beschikkingen niet achteraf hun onaantastbaarheid verliezen. Dat beperkt de bovenindividuele gevolgen uiteraard.

Problematischer wordt de rechtsmachtverdeling wanneer niet naar het verleden van opengestane rechtsgangen wordt gekeken, maar naar voren, naar rechtsgangen die (mogelijkerwijs) nog komen open te staan. De harde basisregel uit arresten als Privacy First is dat de civiele rechter zich afzijdig houdt wanneer rechtsvragen over algemeen verbindende voorschriften aan de orde worden gesteld die ook in bestuursrechtelijke procedures tegen besluiten naar voren kunnen worden gebracht. Een belangenorganisatie die opkomt voor de gebundelde belangen van personen is niet-ontvankelijk in een vordering bij de burgerlijke rechter, als die vordering

19. ABRvS 17 oktober 2018, ECLI:NL:RVS:2018:3324

20. HR 20 januari 2017, ECLI:NL:HR:2017:58 (Alcoholslotprogramma).

21. HR 16 oktober 1992, ECLI:NL:HR:1992:ZC0718 (Vulhop). 
ertoe strekt om ten behoeve van deze personen de onverbindendheid van een verplichting door de burgerlijke rechter te laten vaststellen en ter zake een voorziening te treffen, wanneer die verplichting zich concretiseert bij een appellabel besluit. ${ }^{22}$

Wat dient echter te worden geoordeeld wanneer de bestuursrechter zich over een vraagpunt zou moeten buigen, omdat dat bij de toetsing van besluiten aan de orde kan worden gesteld, maar het nog niet duidelijk is of hij dat daadwerkelijk zal gaan doen? Men zou zeggen dat ook in dat geval de civiele rechter zou moeten terugtreden. De Haagse rechtbank denkt daar in de bodemprocedure over luchtkwaliteit echter anders over.

Zoals al gememoreerd is, was een van de vorderingen dat de Staat zich zou moeten gaan houden aan WHOguidelines voor luchtkwaliteit, die strenger zijn dan de verplichtingen die voor de Staat voortvloeien uit Richtlijn 2008/50/EG en de Wm. Dat is een vordering die ook in bestuursrechtelijke procedures tegen besluiten aan de orde kan komen. Volgens de rechtbank kan de toetsing door de bestuursrechter uitmonden in de conclusie dat een andere norm - in dit geval de WHOnormen - in de plaats van de bestreden wettelijke norm dient te worden gesteld en (binnen afzienbare tijd) moet worden gehaald. Of dat gebeurt, hangt echter af van de formulering van de overwegingen in de uitspraak. De bestuursrechter kan evengoed volstaan met de overweging dat de norm uit de Wm strijdig is met een ieder verbindende verdragsbepaling. Dat is ter vrije bepaling van de bestuursrechter, die slechts gehouden is om op grond van art. 94 van de Grondwet wetgeving die strijdig is met ieder verbindende verdragsbepalingen buiten toepassing te laten en een van de in art. 8:70 Awb opgesomde beslissingen dient te nemen. De bestuursrechter kan dus onbesproken laten of de WHO-normen in de plaats moeten treden van de grenswaarden van de $\mathrm{Wm}$, aldus de rechtbank.

Het is juist dat de bestuursrechter exceptieve toetsing kan nalaten wanneer hij daarvoor geen termen aanwezig acht. In het licht van strenge arresten als Privacy First zou de enkele mogelijkheid van exceptieve toetsing door de bestuursrechter de civiele rechter al tot terugtred moeten brengen. Het is zo dat die jurisprudentie van de Hoge Raad niet allerwegen wordt gedeeld. ${ }^{23}$ Dat zou voor de rechtbank echter geen reden moeten zijn om haar expliciet aan overwegingen ten grondslag te leggen, maar vervolgens niet te volgen.

22. HR 22 mei 2015, ECLI:NL:HR:2015:1296 (Privacy First) en HR 3 juli 2016, ECLI:NL:HR:2016:1049 (SCAU/Universiteiten).

23. Zie P.J. Huisman \& G.A. van der Veen, Bestuursproces(recht) als partijengeding, de beperkte toegang voor belangenorganisaties en enige overwegingen ter verruiming daarvan, in: R.J.N. Schlössels e.a. (red.), In het nu... Over toekomstig bestuursrecht, Deventer: Wolters Kluwer 2018, p. 79-101.

\section{Het aandachtspunt van de geldende norm en de werking van hoger beroep in civilibus}

Ook bij strategisch procederen in het milieurecht is relevant welke normen nu eigenlijk gelden voor het grote maatschappelijke vraagstuk dat partijen aan de rechter willen voorleggen.

Wanneer dat vraagstuk geconcretiseerd is in harde normen, is de vraagstelling voor de burgerlijke rechter nog vrij eenvoudig. De vraag is dan immers of de aangeklaagde partij nu wel of niet aan de harde norm heeft voldaan. Dat blijkt duidelijk uit de procedures inzake de luchtkwaliteit: de rechter in kort geding was van oordeel dat de Staat de periode van overschrijding van de normen niet 'zo kort mogelijk' had gehouden en dusdoende in strijd had gehandeld met de harde eisen van Richtlijn 2008/50/EG.$^{24}$ De bodemrechter oordeelde dat eisers onvoldoende hadden gesteld en bewezen om tot die conclusie te kunnen komen. ${ }^{25}$

Wanneer het maatschappelijke vraagstuk nog niet de kinderschoenen van normstelling ontgroeid is, wordt het lastiger. Dat geldt te meer wanneer de ontwikkeling van het vraagstuk zelf nog volop voortgaat. Dat is te zien in de klimaatzaak. De dagvaarding dateert van eind 2013. Medio 2015 wees de rechtbank vonnis. In het najaar van 2018 wees het hof arrest. Vijf jaar - nog zonder de mogelijkheid van cassatie - is erg lang voor een maatschappelijk vraagstuk dat zelf in ontwikkeling is en zich nog ontwikkelende normen kent. Zo kwam in de klimaatzaak het niet-onbelangrijke akkoord van Parijs van december 2015 voorbij, waarmee landen zich onderling wilden verplichten om klimaatdoelstellingen te behalen.

Hoe moet de civiele rechter met dergelijke schuivende panelen omgaan? In hoeverre dienen in de klimaatzaak bijvoorbeeld nieuwe inzichten ten aanzien van de effecten van klimaatverandering of nieuwe onderzoeks- en/ of meetresultaten te worden meegenomen in de procedure, en waartoe moet dat dan leiden? Ten tijde van de dagvaarding bestond een vrij algemene overtuiging dat de temperatuurstijging niet meer dan twee graden Celsius boven het pre-industriële niveau diende te bedragen. De dagvaarding was dan ook daarop gebaseerd. Intussen is het inzicht opgekomen dat de stijging beperkt zou moeten worden tot maximaal anderhalve graad Celsius. Dat is dan ook als doelstelling in het Akkoord van Parijs vervat. Zou in een hoger beroep - en tot wanneer dan? - de vordering nog dienovereenkomstig kunnen worden aangescherpt?

Hier komt in beeld wat de werking van een hoger beroep en de taak van de appelrechter in dat verband

24. Rb. Den Haag (vz.) 7 september 2017, ECLI:NL:RBDHA:2017:10171.

25. Rb. Den Haag 27 december 2017, ECLI:NL:RBDHA:2017:15380. 
zijn. In hoger beroep vindt een herbeoordeling van de oorspronkelijke vordering plaats. Het gaat derhalve niet om een beoordeling ex tunc van het vonnis in eerste aanleg, maar ex nunc om een beoordeling van de vordering op basis van de processuele stand van zaken ten tijde van de uitspraak in hoger beroep. Partijen kunnen dus in appel hun stellingen aanpassen en wijzigen, bijvoorbeeld in het licht van nieuwe feitelijke ontwikkelingen, nieuwe rechtspraak of nieuwe wetgeving. Dit houdt dan ook in dat feiten die zich pas na de uitspraak in eerste aanleg hebben voorgedaan, in hoger beroep alsnog aan de orde kunnen komen. Met inachtneming van dit alles dient de appelrechter het geschil in beginsel te beoordelen naar het moment van zijn beslissing. ${ }^{26}$

Bij grote maatschappelijke vraagstukken die zich nog aan het uitkristalliseren zijn, kan het risico optreden dat partijen en de rechter door feiten en inzichten worden ingehaald. Gesteld dat tussen 2013 en 2018 een algemeen inzicht zou zijn gerezen dat de tweegradendoelstelling volstrekt onvoldoende zou zijn, dan zou Urgenda ook in 2018 wellicht nog best iets aan de bevestiging van een vordering uit 2013 kunnen hebben, maar een actuelere vordering zou hebben kunnen leiden tot een actueler rechterlijk oordeel. Anders dan in de eerste aanleg leken partijen het bovendien bij de pleidooien in hoger beroep in deze zaak op belangrijke punten oneens te zijn over de waarde van verschillende inzichten over de daadwerkelijke temperatuurstijging. Ook dat maakt het voor de rechter lastig om een ijkpunt te kiezen als basis voor het oordeel. Bij de berechting van grote maatschappelijke vraagstukken kan het resultaat zijn dat de rechter gedurende de looptijd van de procedure door feiten of ontwikkelingen wordt ingehaald. ${ }^{27}$

\section{Het aandachtspunt van de bewijslast en de verhouding met bestuursrechtelijke procedures}

Het bewijsrecht in civiele (bodem)procedures is streng. Volgens art. 150 van het Wetboek van Burgerlijke Rechtsvordering (Rv) draagt de partij die zich beroept op rechtsgevolgen van door haar gestelde feiten of rechten de bewijslast van die feiten of rechten, tenzij uit enige bijzondere regel of uit de eisen van redelijkheid en billijkheid een andere verdeling van de bewijslast voortvloeit. Dat kan problemen opleveren bij het bewijs van onrechtmatigheid van grote maatschappelijke vraagstukken.

Aldus - aanzienlijk uitgebreider en voorzien van veel verwijzingen - A-C Hartlief, conclusie van 8 juni 2018, ECLI:NL:PHR:2018:581.

27. Dit los van diverse vragen die verder naar aanleiding van de procedure van Urgenda gesteld kunnen worden. Zie daarvoor bijv. de annotaties van T.G. Oztürk en G.A. van der Veen bij het vonnis in O\&A 2015/23 en bij het arrest in O\&A 2018/51.

Dat blijkt uit de luchtkwaliteitszaak. Volgens de rechtbank diende Milieudefensie te bewijzen dat de periode van overschrijding van de luchtkwaliteitseisen uit de Europese richtlijn niet 'zo kort mogelijk' was. Het is uiteraard de vraag of die strenge invulling van art. 150 Rv ook in het lopende hoger beroep blijft staan. Die mogelijkheid bestaat. Dus zou Milieudefensie zekerheidshalve moeten ingaan op de specifieke plaatsen van de (gestelde) overschrijdingen, de daar spelende bronnen van vervuiling en de reeds genomen en/of ten onrechte niet genomen maatregelen. Dan kan het hof per locatie in ieder geval inhoudelijker beoordelen of de overschrijding van de grenswaarden zo kort mogelijk is of was, en dus ook of ergens meer vaart gemaakt had moeten worden, ongeacht of het hof het strenge oordeel van de rechtbank op het punt van de (ontbrekende) bewijslevering volgt. ${ }^{28}$

Echter, wanneer die route gevolgd wordt, is de stap naar bestudering van mogelijkerwijs te nemen verkeers- en/ of andere bestuursrechtelijke besluiten niet ver weg. Dan zouden die besluiten dus ook kunnen worden aangevraagd en kan tegen het niet, niet tijdig of ongenoegzaam nemen van die besluiten bestuursrechtelijk geprocedeerd worden. De harde jurisprudentie van arresten als Privacy First sluit voor dat soort gevallen vervolgens civielrechtelijk procederen uit. De combinatie van streng bewijsrecht in civiele procedures en de rechtsmachtverdeling zou dus tot een stevige beperking van het strategisch procederen bij de civiele rechter kunnen leiden.

Het is dan wel zo dat belangenbehartigers ook in bestuursrechtelijke procedures duidelijk dienen te maken welke beslissingen zij dan daadwerkelijk van daartoe bevoegde bestuursorganen verlangen. ${ }^{29}$ Ook in zoverre zien wij dat voor het strategisch procederen over grote maatschappelijke vraagstukken minder ruimte wordt gegund wanneer zo'n vraagstuk zich kan laten herleiden tot één of meer concrete casus.

\section{Conclusie}

Deze bijdrage ging over strategisch procederen in het milieurecht. Bij de bestuursrechter is strategisch procederen gewoon het aanvechten van beschikkingen, met de gewone beperkingen die daarin nu eenmaal gelden. In zoverre is er dus niets nieuws onder de zon. Dat is wel het geval in procedures bij de civiele rechter, getuige recente zaken over klimaatverandering en luchtkwaliteit. Strategisch procederen bij de civiele rechter is echter alleen al door de rechtsmachtverdeling een enorme hordenloop. Strenge eisen aan bewijs en nieuwe inzichten kunnen invloed hebben op de duurzaamheid van bereikte successen.

28. Haag 27 december 2017, ECLI:NL:RBDHA:2017:15380, AB 2018/115. 29. 